\title{
Association of White Matter Hyperintensity Markers on MRI and Long-term Risk of Mortality and Ischemic Stroke
}

\section{The SMART-MR Study}

Rashid Ghaznawi, MD, MSc, Mirjam I. Geerlings, PhD, Myriam Jaarsma-Coes, MSc, Jeroen Hendrikse, MD, PhD, and Jeroen de Bresser, MD, PhD, on behalf of the UCC-Smart Study Group

Neurology ${ }^{\circledR}$ 2021;96:e2172-e2183. doi:10.1212/WNL.0000000000011827

\section{Abstract}

\section{Objective}

To determine whether white matter hyperintensity (WMH) markers on MRI are associated with long-term risk of mortality and ischemic stroke.

\section{Methods}

We included consecutive patients with manifest arterial disease enrolled in the Second Manifestations of Arterial Disease-Magnetic Resonance (SMART-MR) study. We obtained WMH markers (volume, type, and shape) from brain MRI scans performed at baseline using an automated algorithm. During follow-up, occurrence of death and ischemic stroke was recorded. Using Cox regression, we investigated associations of WMH markers with risk of mortality and ischemic stroke, adjusting for demographics, cardiovascular risk factors, and cerebrovascular disease.

\section{Results}

We included 999 patients (59 \pm 10 years; 79\% male) with a median follow-up of 12.5 years (range $0.2-16.0$ years). A greater periventricular or confluent WMH volume was independently associated with a greater risk of vascular death (hazard ratio [HR $1.29,95 \%$ confidence interval [CI] 1.13-1.47) for a 1-unit increase in natural log-transformed $\mathrm{WMH}$ volume and ischemic stroke (HR 1.53, 95\% CI 1.26-1.86). A confluent WMH type was independently associated with a greater risk of vascular (HR 1.89, 95\% CI 1.15-3.11) and nonvascular death (HR 1.65, 95\% CI 1.01-2.73) and ischemic stroke (HR 2.83, 95\% CI 1.36-5.87). A more irregular shape of periventricular or confluent $\mathrm{WMH}$, as expressed by an increase in concavity index, was independently associated with a greater risk of vascular (HR 1.20, 95\% CI 1.05-1.38 per SD increase) and nonvascular death (HR 1.21, 95\% CI 1.03-1.42) and ischemic stroke (HR 1.28, 95\% CI 1.05-1.55).

\section{Conclusions}

$\mathrm{WMH}$ volume, type, and shape are associated with long-term risk of mortality and ischemic stroke in patients with manifest arterial disease.

\author{
Correspondence \\ Dr. Geerlings \\ m.geerlings@umcutrecht.nl
}

\section{RELATED ARTICLE}

\section{Editorial}

White Matter

Hyperintensities: How

Much (and What Shape) Is Too Much?

Page 781

From the Department of Radiology (R.G., J.H.) and Julius Center for Health Sciences and Primary Care (R.G., M.I.G.), University Medical Center Utrecht and Utrecht University; and Department of Radiology (M.J.-C., J.d.B.), Leiden University Medical Center, the Netherlands.

Go to Neurology.org/N for full disclosures. Funding information and disclosures deemed relevant by the authors, if any, are provided at the end of the article. 


\section{Glossary}

CI = confidence interval; CSVD = cerebral small vessel disease; FLAIR = fluid-attenuated inversion recovery; HR = hazard ratio; SMART-MR = Second Manifestations of Arterial Disease-Magnetic Resonance; TE = echo time; TI = inversion time; $\mathbf{T R}=$ repetition time; $\mathbf{W M H}=$ white matter hyperintensities.

White matter hyperintensities (WMH) of presumed vascular origin are frequently observed in older individuals on brain MRI and are an important cause of cognitive decline and dementia. ${ }^{1-3}$ They are considered hallmark features of cerebral small vessel disease (CSVD).,

$\mathrm{WMH}$ are heterogeneous lesions that correspond to different underlying brain parenchymal changes. ${ }^{6-8}$ Previous studies on CSVD mainly focused on WMH volume as a marker for CSVD severity. ${ }^{4,9-12}$ However, there is evidence to suggest that other markers of WMH may also provide clinically relevant information on severity and prognosis of CSVD. ${ }^{6,7,13-16}$ Specifically, histopathologic studies reported that smooth and periventricular WMH are associated with mild changes of the brain parenchyma, whereas irregular and confluent WMH are associated with more severe parenchymal changes, including loss of myelin and incomplete parenchymal destruction. ${ }^{6,13} \mathrm{We}$ previously developed an automated MRI method to assess in vivo advanced WMH markers (volume, type, and shape). ${ }^{14}$ Using this algorithm, we reported differences in advanced WMH markers such as shape in frail elderly patients, patients with diabetes mellitus, and patients with lacunes on MRI. ${ }^{14-16}$ These findings suggest that advanced WMH MRI markers may provide clinically important information on CSVD severity.

The relationship between advanced WMH markers and longterm clinical outcomes, however, is not clear. Examining this relationship is of importance as WMH markers may aid in future patient selection for preventive treatment to ameliorate the risk of CSVD-related death and ischemic stroke. Therefore, in the present study, we aimed to assess whether WMH volume, type, and shape were associated with greater risk of mortality (including vascular death) and ischemic stroke in patients with manifest arterial disease over 12 years of follow-up.

\section{Methods}

\section{Standard Protocol Approvals, Registrations, and Patient Consents}

The Second Manifestations of Arterial Disease-Magnetic Resonance (SMART-MR) study was approved by the medical ethics committee of the University Medical Center Utrecht according to the guidelines of the Declaration of Helsinki of 1975. Written informed consent was obtained from all patients participating in the SMART-MR study.

\section{Study Population}

We used data from the SMART-MR study. ${ }^{17}$ The SMARTMR study is a prospective cohort study at the University
Medical Center Utrecht with the aim of investigating risk factors and consequences of brain changes on MRI in patients with manifest arterial disease. ${ }^{17} \mathrm{~A}$ total of 1,309 middle-aged and older adult patients referred to our medical center for treatment of manifest arterial disease (cerebrovascular disease, manifest coronary artery disease, abdominal aortic aneurysm, or peripheral arterial disease) were included for baseline measurements between 2001 and 2005. ${ }^{17}$ During a 1-day visit to the University Medical Center Utrecht, ultrasonography of the carotid arteries to measure the intimamedia thickness $(\mathrm{mm})$, blood and urine samplings, a physical examination, neuropsychological assessment, and a $1.5 \mathrm{~T}$ brain MRI scan were performed. ${ }^{17}$ We used questionnaires for the assessment of demographics, medical history, risk factors, medication use, and cognitive and physical functioning. ${ }^{17}$

\section{Vascular Risk Factors}

We assessed age, sex, smoking habits, and alcohol intake at baseline using questionnaires. The body mass index (BMI) was calculated $\left(\mathrm{kg} / \mathrm{m}^{2}\right)$ by measuring weight and height. We measured systolic blood pressure $(\mathrm{mm} \mathrm{Hg}$ ) and diastolic blood pressure $(\mathrm{mm} \mathrm{Hg}) 3$ times with a sphygmomanometer and the average of these measurements was calculated. Hypertension was defined as a mean systolic blood pressure of $>160 \mathrm{~mm} \mathrm{Hg}$, a mean diastolic blood pressure of $>95 \mathrm{~mm} \mathrm{Hg}$, or the self-reported use of antihypertensive drugs. ${ }^{17}$ To determine glucose and lipid levels, an overnight fasting venous blood sample was taken. We defined diabetes mellitus as a fasting serum glucose level of $\geq 7.0 \mathrm{mmol} / \mathrm{L}$ or use of glucoselowering medication or a known history of diabetes. ${ }^{17}$ The degree of carotid artery stenosis at both sides was assessed with color Doppler-assisted duplex scanning using a $10 \mathrm{MHz}$ linear-array transducer (ATL Ultramark 9). ${ }^{18}$ Blood flow velocity patterns were used to evaluate the severity of carotid artery stenosis and the greatest stenosis observed on the left or right side of the common or internal carotid artery was taken to determine the severity of carotid artery disease. ${ }^{18}$ We defined a carotid artery stenosis $\geq 70 \%$ as a peak systolic velocity $>210 \mathrm{~cm} / \mathrm{s}^{18}$

\section{Brain MRI}

MRI of the brain was performed on a 1.5 T whole-body system (Gyroscan ACS-NT; Philips Medical Systems, Best, the Netherlands) using a standardized scan protocol. ${ }^{17,19}$ Transversal fluid-attenuated inversion recovery (FLAIR) (repetition time [TR] 6,000 ms; echo time [TE] $100 \mathrm{~ms}$; inversion time [TI] 2,000 ms), T1-weighted (TR $235 \mathrm{~ms}$; TE $2 \mathrm{~ms}$ ), T1-weighted inversion recovery (TR 2,900 ms; TE $22 \mathrm{~ms}$; TI $410 \mathrm{~ms}$ ), and T2-weighted images (TR 2,200 ms; TE $11 \mathrm{~ms}$ ) were acquired with a voxel size of $1.0 \times 1.0 \times 4.0 \mathrm{~mm}^{3}$ and 
Figure 1 White Matter Hyperintensities (WMH) on Fluid-Attenuated Inversion Recovery (FLAIR) Images With Corresponding Visualizations in the Automated Algorithm

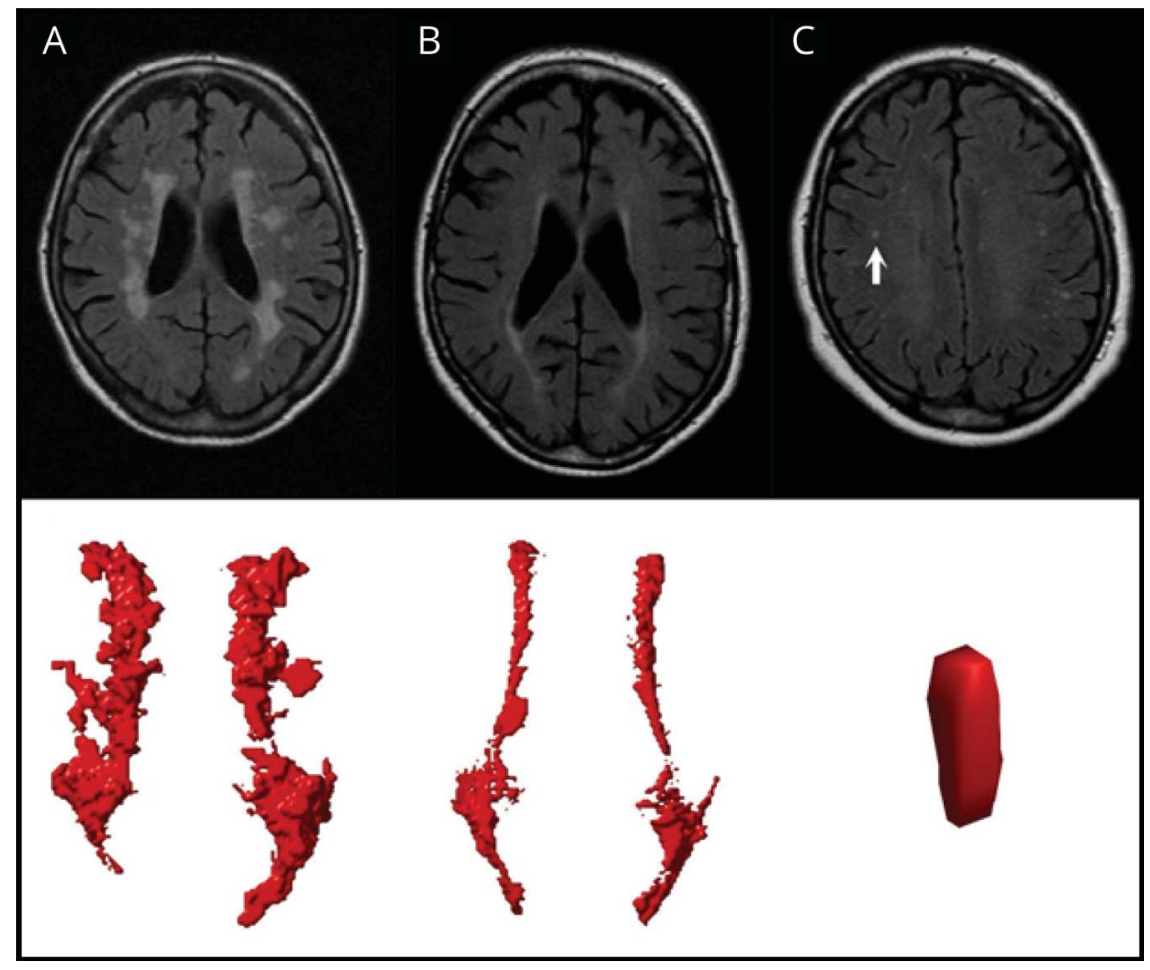

Examples of confluent (A), periventricular (B), and deep (C) WMH on FLAIR images with the corresponding visualizations in our algorithm shown below. The deep WMH lesion (arrow) is reconstructed in the coronal view, while the periventricular and confluent WMH are viewed from a transverse perspective. Note that the coronal reconstruction of the deep WMH lesion (C) may be influenced by the slice thickness and the lesion may be more punctiform. The confluent $\mathrm{WMH}$ lesion in (A) showed a volume of $11.57 \mathrm{~mL}$ with an accompanying deep $\mathrm{WMH}$ volume of $0.25 \mathrm{~mL}$. The periventricular $\mathrm{WMH}$ lesion in (B) showed a volume of $4.98 \mathrm{~mL}$ without any accompanying deep WMH lesions. The deep WMH lesion in (C) showed a volume of $0.02 \mathrm{~mL}$ with an accompanying periventricular and deep $\mathrm{WMH}$ volume of 2.12 and $0.49 \mathrm{~mL}$, respectively.

contiguous slices. ${ }^{14,19}$ A neuroradiologist blinded to patient characteristics visually rated brain infarcts on the T1weighted, T2-weighted, and FLAIR images of the MRI scans. We defined lacunes as focal lesions between 3 and $15 \mathrm{~mm}$ according to the STRIVE criteria. ${ }^{4}$ Nonlacunar lesions were categorized into large infarcts (i.e., cortical infarcts and subcortical infarcts not involving the cerebral cortex) and those located in the brainstem or cerebellum. ${ }^{14}$

\section{WMH Volumes}

$\mathrm{WMH}$ and brain volumes (intracranial volume and total brain volume) were obtained using the $k$-nearest neighbor ( $\mathrm{kNN}$ ) automated segmentation program on the T1-weighted, FLAIR, and T1-weighted inversion recovery sequences of the MRI scans. ${ }^{19,20}$ WMH segmentations were visually assessed by an investigator (R.G.) using an image processing framework (MeVisLab 2.7.1.; MeVis Medical Solutions AG, Bremen, Germany) to ensure that cerebral infarcts were correctly removed from the WMH segmentations. ${ }^{14}$ Next, we performed ventricle segmentation using the fully automated lateral ventricle delineation (ALVIN) algorithm in Statistical Parametric Mapping 8 (SPM8, Wellcome Trust Centre for Neuroimaging, University College London, UK) for MATLAB (The MathWorks, Inc., Natick, MA). ${ }^{14}$ The procedure is described in detail elsewhere. ${ }^{14,21}$ We labeled WMH according to their continuity with the margins of the lateral ventricle and their extension from the lateral ventricle into the white matter. ${ }^{14}$ Periventricular WMH were defined as lesions contiguous with the margins of the lateral ventricles and extending up to $10 \mathrm{~mm}$ from the lateral ventricle into the white matter. ${ }^{14}$ We defined confluent WMH as lesions contiguous with the margins of the lateral ventricles and extending more than $10 \mathrm{~mm}$ from the lateral ventricles into the white matter. ${ }^{14}$ We defined deep WMH as lesions that were separated from the margins of the lateral ventricles. ${ }^{14}$ Examples of periventricular, confluent, and deep WMH visualized in our algorithm are shown in figure 1. Total WMH volume was calculated as the sum of deep $\mathrm{WMH}$ and periventricular or confluent WMH.

\section{WMH Types}

We categorized patients into the following $3 \mathrm{WMH}$ types: periventricular WMH type without deep WMH, periventricular WMH type with deep WMH, and a confluent WMH type. We did not categorize the latter type according to presence or absence of deep WMH as the number of patients with a confluent WMH without deep WMH $(\mathrm{n}=5)$ was insufficient to perform statistical analyses. ${ }^{14}$

\section{WMH Shape Markers}

We hypothesized that a more irregular shape of WMH may indicate more severe cerebral parenchymal damage based on previous histopathologic studies. ${ }^{6-8,13,22,23}$ The degree to which deep WMH are punctiform or ellipsoidal may also provide information on CSVD severity. ${ }^{15}$

Irregularity of periventricular or confluent $\mathrm{WMH}$ was quantified using the concavity index and fractal dimension. In 
Table 1 Baseline Characteristics of the Study Sample $(n=999)$

\begin{tabular}{|c|c|}
\hline Characteristics & Values \\
\hline Age, y & $59 \pm 10$ \\
\hline Sex, \% men & 79.0 \\
\hline BMI, $\mathrm{kg} / \mathrm{m}^{2}$ & $27 \pm 4$ \\
\hline Smoking, pack-years ${ }^{a}$ & $18(0,50)$ \\
\hline Alcohol intake, \% current & 74 \\
\hline Hypertension, \% & 51 \\
\hline Diabetes mellitus, \% & 20 \\
\hline \multicolumn{2}{|l|}{ Infarcts on MRI, \% } \\
\hline Large & 12 \\
\hline Cerebellar & 4 \\
\hline Brainstem & 2 \\
\hline Lacunes & 19 \\
\hline \multicolumn{2}{|l|}{ WMH volumes, $\mathrm{mL}^{\mathrm{a}}$} \\
\hline Total & $0.9(0.2,6.4)$ \\
\hline Periventricular or confluent & $0.7(0.1,5.3)$ \\
\hline Deep & $0.1(0.0,0.8)$ \\
\hline \multicolumn{2}{|l|}{ WMH types, \% } \\
\hline Periventricular & 78 \\
\hline With deep & 42 \\
\hline Without deep & 36 \\
\hline Confluent & 22 \\
\hline \multicolumn{2}{|l|}{ WMH shape markers } \\
\hline \multicolumn{2}{|l|}{ Periventricular or confluent } \\
\hline Concavity index & $1.06 \pm 0.11$ \\
\hline Fractal dimension & $1.24 \pm 0.22$ \\
\hline \multicolumn{2}{|l|}{ Deep } \\
\hline Eccentricity & $0.48 \pm 0.14$ \\
\hline Fractal dimension & $1.45 \pm 0.15$ \\
\hline
\end{tabular}

Abbreviations: $\mathrm{BMI}=$ body mass index; $\mathrm{WMH}=$ white matter hyperintensities .

Characteristics are presented as mean \pm SD or \%.

a Median (10th percentile, 90th percentile).

previous work, we established that the concavity index was a robust shape marker that showed a normal distribution in the study sample and provided information on WMH shape irregularity based on volume and surface area. ${ }^{14,24}$ The concavity index was calculated by reconstructing convex hulls and calculating volume and surface area ratios of lesions, in which a higher concavity index value corresponds to a more irregular shape of periventricular or confluent WMH. ${ }^{14}$ Fractal dimension was calculated using the box counting method and was used to quantify irregularity of periventricular or confluent WMH and of deep WMH. ${ }^{14,25,26}$ A higher fractal dimension value indicated a more irregular WMH shape. As patients frequently show multiple deep $\mathrm{WMH}$, a mean value for the fractal dimension was calculated across all deep WMH per patient.

The degree to which deep WMH are punctiform or ellipsoidal was assessed using the eccentricity, which was calculated by dividing the minor axis of a deep WMH lesion by its major axis. $^{14,15}$ A high eccentricity value corresponded to a 
Table 2 Results of Cox Proportional Hazard Regression Analyses With Total, Periventricular or Confluent, and Deep White Matter Hyperintensity (WMH) Volumes (All Natural Log-Transformed) as Independent Variables and All-Cause, Vascular-Related, and Nonvascular-Related Death and Ischemic Stroke as Dependent Variables

\begin{tabular}{|c|c|c|c|c|}
\hline & Deaths or events, $n$ & $\mathrm{~N}$ per 1,000 person-years & Model 1, estimate $(95 \% \mathrm{Cl})$ & Model 2 , estimate $(95 \% \mathrm{Cl})$ \\
\hline \multicolumn{5}{|l|}{ Total WMH } \\
\hline All-cause death & 274 & 24.2 & $1.32(1.19-1.46)$ & $1.22(1.10-1.36)$ \\
\hline Vascular death & 149 & 13.2 & $1.47(1.29-1.68)$ & $1.32(1.14-1.51)$ \\
\hline Nonvascular death & 125 & 11.1 & $1.15(0.99-1.34)$ & $1.11(0.95-1.30)$ \\
\hline Ischemic stroke & 75 & 6.8 & $1.79(1.48-2.16)$ & $1.58(1.29-1.93)$ \\
\hline \multicolumn{5}{|c|}{ Periventricular or confluent WMH } \\
\hline All-cause death & 274 & 24.2 & $1.29(1.17-1.42)$ & $1.20(1.09-1.33)$ \\
\hline Vascular death & 149 & 13.2 & $1.43(1.26-1.63)$ & $1.29(1.13-1.47)$ \\
\hline Nonvascular death & 125 & 11.1 & $1.14(0.99-1.32)$ & $1.10(0.95-1.28)$ \\
\hline Ischemic stroke & 75 & 6.8 & $1.73(1.45-2.08)$ & $1.53(1.26-1.86)$ \\
\hline \multicolumn{5}{|l|}{ Deep WMH } \\
\hline All-cause death & 212 & 30.8 & $1.13(1.04-1.24)$ & $1.10(1.01-1.21)$ \\
\hline Vascular death & 122 & 17.8 & $1.15(1.03-1.30)$ & $1.11(0.98-1.25)$ \\
\hline Nonvascular death & 90 & 13.1 & $1.10(0.96-1.26)$ & $1.10(0.96-1.26)$ \\
\hline Ischemic stroke & 62 & 9.4 & $1.24(1.05-1.46)$ & $1.18(0.99-1.40)$ \\
\hline
\end{tabular}

Abbreviation: $\mathrm{Cl}=$ confidence interval.

Estimates represent hazard ratios $(95 \% \mathrm{Cl})$ for a 1 unit increase in natural log-transformed WMH volumes. Model 1: adjusted for age, sex, and intracranial volume. Model 2: model 1 in addition adjusted for large infarcts on MRI, lacunes on MRI, diastolic blood pressure, systolic blood pressure, diabetes mellitus, body mass index, and smoking pack-years at baseline.

punctiform deep WMH lesion, whereas a low value corresponded to an ellipsoidal lesion. ${ }^{27,28}$ A mean value for the eccentricity was calculated across all deep WMH per patient.

\section{Clinical Outcomes}

Patients received a questionnaire every 6 months to provide information on outpatient clinic visits and hospitalization. ${ }^{18}$ If a fatal or nonfatal event was reported, original source documents were obtained and reviewed to determine the cause of the event. All possible events were audited independently by 3 physicians of the end point committee. ${ }^{18}$ Follow-up of patients was performed until death, refusal of further participation, or loss to follow-up. Vascular-related death was defined as death caused by myocardial infarction, stroke, sudden death (unexpected cardiac death occurring within 1 hour after onset of symptoms, or within 24 hours given convincing circumstantial evidence), congestive heart failure, or rupture of an abdominal aortic aneurysm. ${ }^{18}$ We defined nonvascular-related death as death caused by cancer, infection, unnatural death, or death from another nonvascular cause. ${ }^{18}$ Ischemic stroke was defined as the occurrence of relevant clinical features that caused an increase in impairment of at least 1 grade on the modified Rankin Scale, with or without a new relevant ischemic lesion on brain imaging. ${ }^{18}$

\section{Study Sample}

Of the 1,309 patients included, MRI data were irretrievable for 19 patients and 239 patients had missing data of one or more MRI sequences due to logistic reasons or motion artifacts. Forty-four of the remaining 1,051 patients had unreliable brain volume data due to motion artifacts in all $3 \mathrm{MRI}$ sequences. Four patients were excluded due to undersegmentation of WMH by the automated segmentation algorithm and another 4 patients were excluded because they did not have any WMH greater than 5 voxels. As a result, 999 patients were included in the current study.

\section{Statistical Analysis}

Baseline characteristics of the study sample were reported as means or percentages where applicable.

Patients were followed from the date of the MRI until ischemic stroke, death, loss to follow-up, or end of follow-up (March 2017), whichever came first. Cox proportional hazard analysis was used to estimate hazard ratios (HRs) for the occurrence of all-cause, vascular-related, and nonvascularrelated death and ischemic stroke associated with WMH volumes, type, and shape markers. The proportional hazards assumption was checked by inspection of Schoenfeld 
Figure 2 Risk of Mortality and Ischemic Stroke in Relation to Quartiles of Periventricular or Confluent White Matter Hyperintensity (WMH) Volume at Baseline
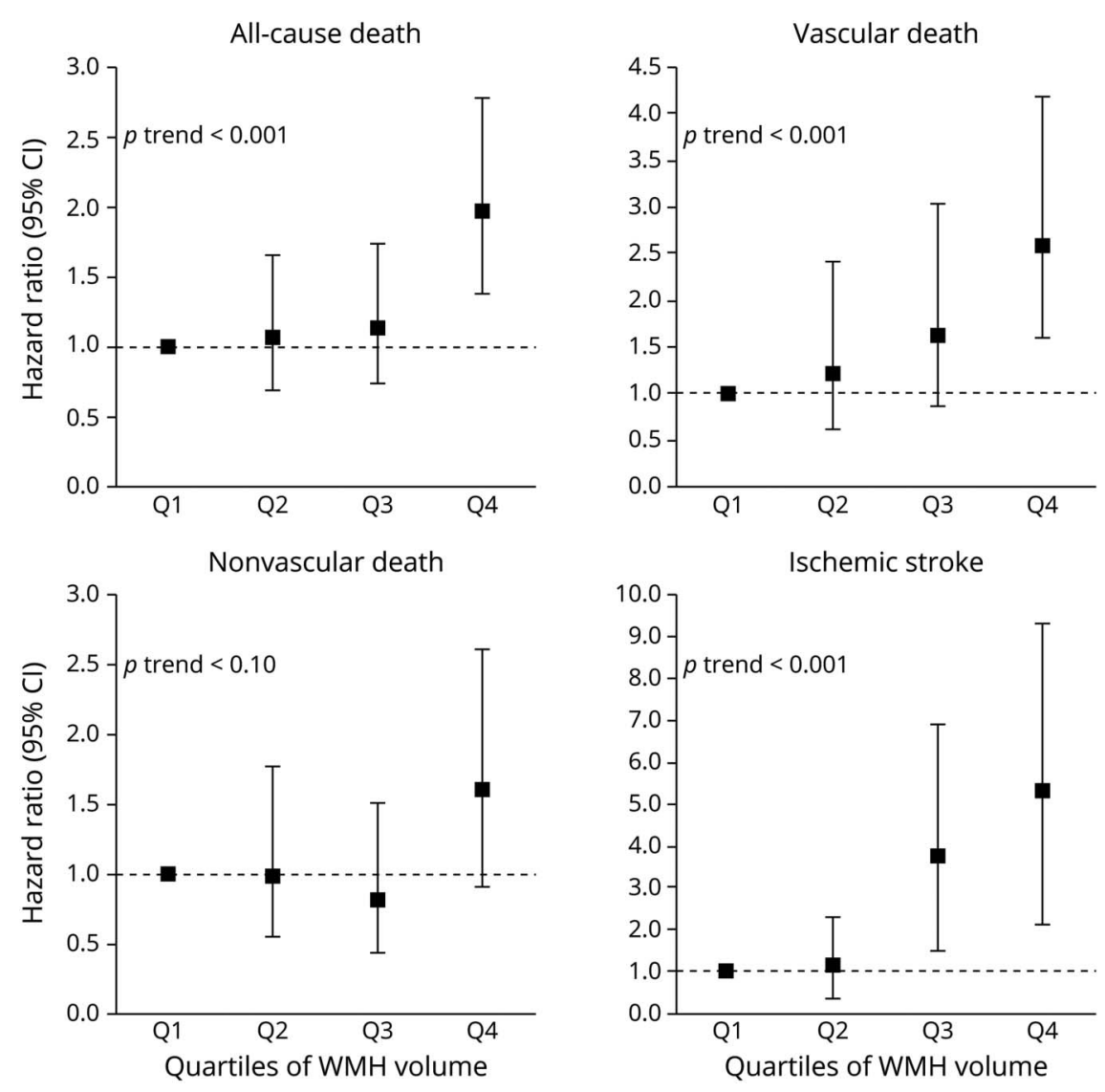

\begin{abstract}
Associations between quartiles of periventricular or confluent $\mathrm{WMH}$ volume and risk of all-cause death, vascular death, nonvascular death, and ischemic stroke. Results adjusted for age, sex, intracranial volume, large infarcts on MRI, lacunes on MRI, diastolic blood pressure, systolic blood pressure, diabetes mellitus, body mass index, and smoking pack-years at baseline. The lowest quartile $(<0.33 \mathrm{~mL})$ was chosen as the reference category. Range second to fourth quartiles; $0.33-0.74 \mathrm{~mL}, 0.74-2.04 \mathrm{~mL}$, $\geq 2.04 \mathrm{~mL}$, respectively. Note that the scale of the $y$-axis may differ between outcomes. Examples of periventricular or confluent WMH from each quartile are shown in supplemental figure e-1 (available from Dryad: doi.org/10.5061/dryad.qv9s4mwd3). $\mathrm{Cl}=$ confidence interval.
\end{abstract}

residuals. We concluded that the proportional hazards assumption was met for all covariates.

To reduce the risk of bias due to complete case analysis, we performed chained equations imputation on missing covariates to generate 10 imputed datasets using SPSS 25.0 (Chicago, IL). ${ }^{29}$ The Cox regression analyses were performed on the imputed datasets and the pooled results were presented. We used SAS 9.4 (SAS Institute, Cary, NC) and SPSS 25.0 (Chicago, IL) to perform the statistical analyses.

\section{WMH Volumes and Clinical Outcomes}

To assess whether WMH volumes were associated with clinical outcomes, we separately entered total, periventricular or confluent, and deep WMH volumes in a Cox regression model with age, sex, and intracranial volume as covariates and all-cause death, vascular-related death, nonvascular-related death, and ischemic stroke as outcomes. WMH volumes were natural log-transformed due to a non-normal distribution. In a second model, we in addition adjusted for large infarcts, lacunes, diastolic blood pressure, systolic blood pressure, diabetes mellitus, body mass index, and smoking pack-years at baseline. We also assessed the association between quartiles of
WMH volumes (not natural log-transformed) and clinical outcomes, adjusted for all of the aforementioned covariates.

\section{WMH Types and Clinical Outcomes}

To assess whether WMH types were associated with clinical outcomes, a categorical variable with the $3 \mathrm{WMH}$ types as outcomes was entered in a Cox regression model with age and sex as covariates and all-cause death, vascular-related death, nonvascular-related death, and ischemic stroke as outcomes. A periventricular WMH type without deep WMH was chosen as the reference category as this type represents the smallest WMH burden. In a second model, we in addition adjusted for the aforementioned covariates.

\section{WMH Shape Markers and Clinical Outcomes}

$Z$ scores of WMH shape markers were calculated to facilitate comparison and these were entered in a Cox regression model with age and sex as covariates and all-cause death, vascularrelated death, nonvascular-related death, and ischemic stroke as outcomes. In a second model, we in addition adjusted for the aforementioned covariates. If an association between a WMH shape marker and clinical outcome was observed, we in addition adjusted for total WMH volume to assess whether the association was independent of WMH volume. 
Figure 3 Risk of Mortality and Ischemic Stroke in Relation to Quartiles of Deep White Matter Hyperintensity (WMH) Volume at Baseline
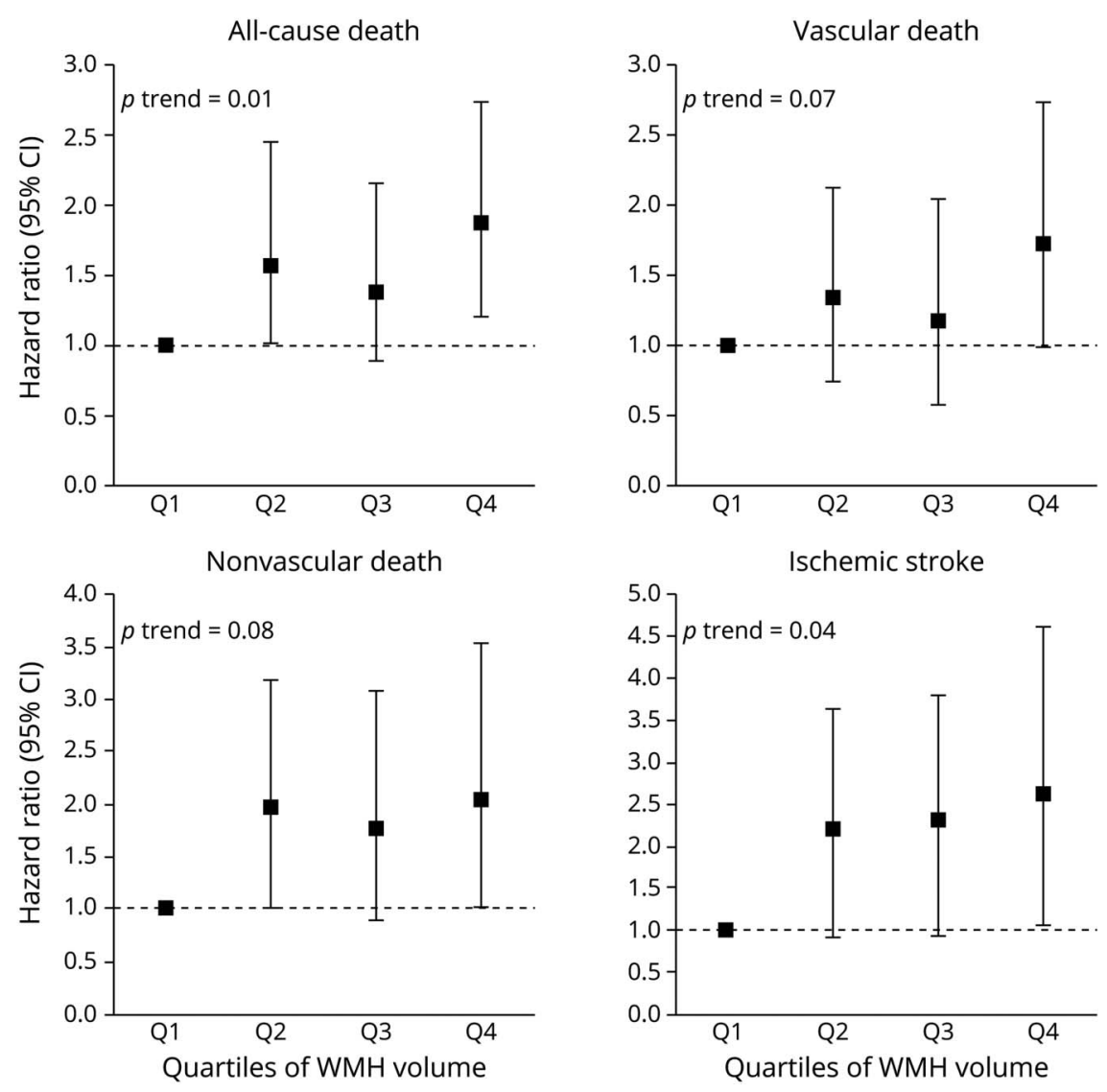

Associations between quartiles of deep $\mathrm{WMH}$
volume and risk of all-cause death, vascular
death, nonvascular death, and ischemic stroke.
Results adjusted for age, sex, intracranial vol-
ume, large infarcts on MRI, lacunes on MRI, di-
astolic blood pressure, systolic blood pressure,
diabetes mellitus, body mass index, and smoking
pack-years at baseline. The lowest quartile ( $<0.03$
$\mathrm{~mL}$ ) was chosen as the reference category. Range
second to fourth quartiles; $0.03-0.08 \mathrm{~mL}$,
$0.08-0.35 \mathrm{~mL}, \geq 0.35 \mathrm{~mL}$, respectively. Note that
the scale of the $y$-axis may differ between out-
comes. $\mathrm{Cl}=$ confidence interval.

\section{Data Availability}

For use of anonymized data, a reasonable request has to be made in writing to the study group and the third party has to sign a confidentiality agreement.

\section{Results}

Baseline characteristics of the study sample $(\mathrm{n}=999)$ are shown in table 1. A total of 784 patients (78\%) had periventricular WMH and 215 patients (22\%) had confluent WMH. A periventricular with deep WMH type was present in 423 patients (42\%) and a periventricular without deep WMH type was present in 361 patients (36\%). In total, 274 patients died (149 vascular-related and 125 nonvascular-related) and 75 patients had an ischemic stroke during a median follow-up of 12.5 years (range $0.2-16.0$ years; total number of personyears follow-up 11,303).

\section{Associations Between WMH Volumes and Long-term Clinical Outcomes}

Greater total WMH volume was associated with all-cause death (HR 1.32, 95\% confidence interval [CI] 1.19-1.46 for a 1-unit increase in natural log-transformed total $\mathrm{WMH}$ volume), particularly vascular-related death (HR 1.47, 95\% CI 1.29-1.68) and to a lesser extent nonvascular-related death (HR 1.15, 95\% CI 0.99-1.34), as well as with ischemic stroke (HR 1.79, 95\% CI 1.48-2.16), adjusted for age, sex, and total intracranial volume. These associations persisted after adjusting for cardiovascular risk factors and cerebrovascular disease (table 2).

Greater periventricular or confluent WMH volume was associated with all-cause death (HR 1.29, 95\% CI 1.17-1.42), particularly vascular-related death (HR 1.43, 95\% CI 1.26-1.63), and to a lesser extent with nonvascular-related death (HR 1.14, 95\% CI 0.99-1.32), as well as with ischemic stroke (HR 1.73, 95\% CI 1.45-2.08). These associations persisted after adjusting for cardiovascular risk factors and cerebrovascular disease (table 2).

Greater deep WMH volume was associated with all-cause death (HR 1.13, 95\% CI 1.04-1.24), vascular-related death (HR 1.15, 95\% CI 1.03-1.30), and more strongly with ischemic stroke (HR 1.24, 95\% CI 1.05-1.46). Risk estimates slightly attenuated after adjusting for cardiovascular risk factors and cerebrovascular disease (table 2). A nonsignificant association was observed between greater deep WMH volume 
Table 3 Results of Cox Proportional Hazard Regression Analyses With White Matter Hyperintensity (WMH) Types as Independent Variables and All-Cause, Vascular-Related, and Nonvascular-Related Death and Ischemic Stroke as Dependent Variables

\begin{tabular}{|c|c|c|c|c|}
\hline & $\begin{array}{l}\text { Deaths or } \\
\text { events, } n\end{array}$ & $\begin{array}{l}\mathrm{N} \text { per } 1,000 \text { person- } \\
\text { years }\end{array}$ & $\begin{array}{l}\text { Model 1, estimate }(95 \% \\
\mathrm{Cl})\end{array}$ & $\begin{array}{l}\text { Model 2, estimate }(95 \% \\
\mathrm{Cl})\end{array}$ \\
\hline \multicolumn{5}{|c|}{ Periventricular without deep WMH $(n=360)$} \\
\hline All-cause death & 60 & 13.7 & 1 (reference) & 1 (reference) \\
\hline Vascular death & 27 & 6.2 & 1 (reference) & 1 (reference) \\
\hline Nonvascular death & 33 & 7.5 & 1 (reference) & 1 (reference) \\
\hline Ischemic stroke & 13 & 3.0 & 1 (reference) & 1 (reference) \\
\hline \multicolumn{5}{|c|}{ Periventricular with deep WMH $(n=424)$} \\
\hline All-cause death & 105 & 21.5 & $1.27(0.92-1.75)$ & $1.14(0.82-1.58)$ \\
\hline Vascular death & 58 & 11.9 & $1.53(0.96-2.42)$ & $1.31(0.82-2.09)$ \\
\hline Nonvascular death & 47 & 9.6 & $1.06(0.68-1.67)$ & $1.01(0.64-1.59)$ \\
\hline Ischemic stroke & 28 & 5.9 & $1.75(0.90-3.41)$ & $1.48(0.75-2.91)$ \\
\hline \multicolumn{5}{|c|}{ Confluent WMH $(n=215)$} \\
\hline All-cause death & 109 & 53.3 & $2.29(1.64-3.19)$ & $1.74(1.23-2.47)$ \\
\hline Vascular death & 64 & 31.3 & $2.81(1.75-4.49)$ & $1.89(1.15-3.11)$ \\
\hline Nonvascular death & 45 & 22.0 & $1.85(1.15-2.98)$ & $1.65(1.01-2.73)$ \\
\hline Ischemic stroke & 34 & 17.8 & $4.36(2.20-8.65)$ & $2.83(1.36-5.87)$ \\
\hline
\end{tabular}

Abbreviation: $\mathrm{Cl}=$ confidence interval.

Estimates represent hazard ratios $(95 \% \mathrm{Cl})$ for WMH types. A periventricular WMH type without deep WMH was the reference category. Model 1: adjusted for age and sex. Model 2: model 1 in addition adjusted for large infarcts on MRI, lacunes on MRI, diastolic blood pressure, systolic blood pressure, diabetes mellitus, body mass index, and smoking pack-years at baseline.

and nonvascular death (HR 1.10, 95\% CI 0.96-1.26), which did not change after adjusting for cardiovascular risk factors and cerebrovascular disease (table 2).

Risk of vascular-related death and ischemic stroke increased per quartile of periventricular or confluent WMH volume (figure 2). Similarly, risk of ischemic stroke increased per quartile of deep WMH volume (figure 3).

\section{Associations Between WMH Types and Long- term Clinical Outcomes}

Compared to a periventricular WMH type without deep $\mathrm{WMH}$, a confluent WMH type was associated with a greater risk of all-cause death (HR 2.29, 95\% CI 1.64-3.19), particularly vascular-related death (HR 2.81, 95\% CI 1.75-4.49) and to a lesser extent nonvascular-related death (HR 1.85, 95\% CI 1.15-2.98), as well as with ischemic stroke (HR 4.36, 95\% CI 2.20-8.65). These associations persisted after adjusting for cardiovascular risk factors and cerebrovascular disease (table 3). Nonsignificant associations were observed between a periventricular WMH type with deep WMH and vascular-related death (HR 1.53, 95\% CI 0.96-2.42) and ischemic stroke (HR 1.75, 95\% CI 0.90-3.41), which attenuated after adjusting for cardiovascular risk factors and cerebrovascular disease (table 3 ).

\section{Associations Between WMH Shape Markers and Long-term Clinical Outcomes}

A greater concavity index of periventricular or confluent $\mathrm{WMH}$ was associated with a greater risk of all-cause death (HR 1.30, 95\% CI 1.18-1.43 per SD increase), particularly vascular-related death (HR 1.34, 95\% CI 1.18-1.52) and to a lesser extent nonvascular-related death (HR 1.25, 95\% CI $1.07-1.45$ ), as well as with ischemic stroke (HR 1.47, 95\% CI 1.23-1.76), adjusted for age and sex. These associations persisted after adjusting for cardiovascular risk factors and cerebrovascular disease (table 4). After in addition adjusting for total WMH volume, the association of concavity index with all-cause and nonvascular-related death persisted (HR 1.21, 95\% CI 1.02-1.42; HR 1.23, 95\% CI 1.02-1.49, respectively), whereas the association with vascular-related death and ischemic stroke attenuated (HR 1.11, 95\% CI 0.89-1.39; HR 1.23, 95\% CI 0.95-1.77, respectively).

A greater fractal dimension of periventricular or confluent WMH was associated with a greater risk of all-cause death (HR 1.33, 95\% CI 1.16-1.52 per SD increase), vascularrelated death (HR 1.52, 95\% CI 1.27-1.82), and ischemic stroke (HR 2.06, 95\% CI 1.60-2.65), adjusted for age and sex. These relationships persisted after adjusting for cardiovascular risk factors and cerebrovascular disease (table 4). After in 
Table 4 Results of Cox Proportional Hazard Regression Analyses With Standardized White Matter Hyperintensity (WMH) Shape Markers as Independent Variables and All-Cause, Vascular-Related, and Nonvascular-Related Death and Ischemic Stroke as Dependent Variables

\begin{tabular}{|c|c|c|c|c|}
\hline & Deaths or events, $n$ & N per 1,000 person-years & Model 1, estimate $(95 \% \mathrm{Cl})$ & Model 2 , estimate $(95 \% \mathrm{Cl})$ \\
\hline \multicolumn{5}{|c|}{ Periventricular or confluent WMH } \\
\hline \multicolumn{5}{|l|}{ Concavity index } \\
\hline All-cause death & 274 & 24.2 & $1.30(1.18-1.43)$ & $1.21(1.09-1.35)$ \\
\hline Vascular death & 149 & 13.2 & $1.34(1.18-1.52)$ & $1.20(1.05-1.38)$ \\
\hline Nonvascular death & 125 & 11.1 & $1.25(1.07-1.45)$ & $1.21(1.03-1.42)$ \\
\hline Ischemic stroke & 75 & 6.8 & $1.47(1.23-1.76)$ & $1.28(1.05-1.55)$ \\
\hline \multicolumn{5}{|l|}{ Fractal dimension } \\
\hline All-cause death & 274 & 24.2 & $1.33(1.16-1.52)$ & $1.19(1.04-1.36)$ \\
\hline Vascular death & 149 & 13.2 & $1.52(1.27-1.82)$ & $1.29(1.08-1.55)$ \\
\hline Nonvascular death & 125 & 11.1 & $1.13(0.92-1.37)$ & $1.06(0.87-1.30)$ \\
\hline Ischemic stroke & 75 & 6.8 & $2.06(1.60-2.65)$ & $1.73(1.33-2.25)$ \\
\hline
\end{tabular}

\section{Deep WMH}

\begin{tabular}{lllll}
\hline Fractal dimension & & & & \\
\hline All-cause death & 212 & 30.8 & $1.03(0.89-1.20)$ & $1.07(0.92-1.26)$ \\
\hline Vascular death & 122 & 17.8 & $1.06(0.87-1.29)$ & $1.11(0.91-1.37)$ \\
\hline Nonvascular death & 90 & 13.1 & $1.00(0.79-1.25)$ & $1.02(0.81-1.29)$ \\
\hline Ischemic stroke & 62 & 9.4 & $0.82(0.63-1.06)$ & $0.85(0.65-1.12)$ \\
\hline Eccentricity & 212 & & $0.93(0.81-1.07)$ & $0.98(0.85-1.14)$ \\
\hline All-cause death & 122 & 30.8 & $1.01(0.84-1.21)$ & $1.09(0.90-1.33)$ \\
\hline Vascular death & 90 & 17.8 & $0.84(0.68-1.04)$ & $0.85(0.68-1.07)$ \\
\hline Nonvascular death & 62 & 13.1 & $0.99(0.77-1.28)$ & $1.14(0.87-1.49)$ \\
\hline Ischemic stroke & 9.4 & & \\
\hline
\end{tabular}

Abbreviation: $\mathrm{Cl}=$ confidence interval.

Estimates represent hazard ratios ( $95 \%$ Cl) for 1 SD increase in the marker. Model 1: adjusted for age and sex. Model 2: model 1 in addition adjusted for large infarcts on MRI, lacunes on MRI, diastolic blood pressure, systolic blood pressure, diabetes mellitus, body mass index, and smoking pack-years at baseline.

addition adjusting for total WMH volume, the association of fractal dimension with all-cause death, vascular-related death, and ischemic stroke attenuated (HR 1.10, 95\% CI 0.93-1.30; HR 1.20, 95\% CI 0.95-1.51; HR 1.09, 95\% CI 0.52-2.27, respectively). A greater fractal dimension of periventricular or confluent WMH was not associated with a greater risk of nonvascular-related death (HR 1.13, 95\% CI 0.92-1.37).

No associations were observed between eccentricity and fractal dimension of deep WMH and long-term clinical outcomes (table 4).

\section{Discussion}

In this cohort of patients with manifest arterial disease, we observed that WMH volume, type, and shape were associated with long-term clinical outcomes. Specifically, we found that a greater volume and a more irregular shape of periventricular or confluent WMH were related to a higher risk of death and ischemic stroke. A confluent WMH type was also associated with a greater risk of death and ischemic stroke. These relationships were independent of demographics, cardiovascular risk factors, and cerebrovascular disease at baseline.

Our finding that total WMH volume was related to risk of mortality and stroke is in line with previous studies..$^{30-34}$ However, the associations of WMH volume subclassifications and WMH types with clinical outcomes presented in this study are novel. We found that the risk of mortality and ischemic stroke was predominantly determined by the volume of periventricular or confluent $\mathrm{WMH}$, rather than the volume of deep WMH. This was supported by the observation that risk estimates for mortality and ischemic stroke were higher 
for a confluent WMH type than a periventricular WMH type with deep WMH. A possible explanation for this finding may be that confluent WMH represent more severe parenchymal changes due to their relatively central location in the brain. Previous studies showed that pathologic changes in the smaller vessels of the brain can induce secondary ischemia, which may be more profound in the white matter surrounding the lateral ventricles as these regions are furthest removed from collateral circulation. ${ }^{4,35}$ This notion may explain the relatively strong association between a confluent WMH type and occurrence of ischemic stroke in the present study.

To our knowledge, no previous studies reported on the longitudinal association of WMH shape with clinical outcomes. In the present study, we observed that a more irregular shape of periventricular or confluent WMH was related to an increased risk of mortality and ischemic stroke, which was only partly explained by $\mathrm{WMH}$ volume. An explanation for this finding may be that CSVD consists of a heterogeneous group of small vessel changes and a more irregular shape of WMH may indicate the presence of a more severe CSVD subtype. 35,36 Support for this notion is provided by histopathologic studies that reported ischemic damage, loss of myelin, and incomplete parenchymal destruction in more irregular shaped WMH, whereas smooth WMH correlated with more benign pathologic changes such as venous congestion. ${ }^{6,8,13}$ Furthermore, a previous study reported an association between a more irregular shape of WMH and frailty in elderly patients ${ }^{16}$ and in previous work we showed that presence of lacunes on MRI was related to a more irregular shape of $\mathrm{WMH}^{14}$ These investigations and the results of the present study suggest that in addition to $\mathrm{WMH}$ volume, shape of WMH may represent a clinically relevant marker in patients with WMH on MRI.

We observed that a confluent WMH type and a more irregular shape of periventricular or confluent WMH were not only associated with a greater risk of vascular death, but also of nonvascular death. In previous work, we similarly reported that presence of lacunes on MRI was related to a greater risk of nonvascular death. ${ }^{37}$ An explanation for these findings is that CSVD may be a marker of overall increased vulnerability to adverse outcomes, possibly through the concomitant presence of generalized microvascular disease. ${ }^{2,4,35}$ Further studies in different cohorts are needed to confirm this hypothesis, but the reported associations with vascular and nonvascular death suggest that WMH markers may be important in determining overall prognosis of patients with manifest arterial disease.

Key strengths of the present study are the large number of patients included, the longitudinal design, the relatively long follow-up period, and the use of automated image processing techniques that enabled us to examine multiple and also novel features of WMH in relation to clinical outcomes. Furthermore, all MRI scans were visually checked and corrected if needed to ensure that WMH segmentation and subsequent analysis of WMH type and shape were accurate.
Limitations of this study include, first, the use of $1.5 \mathrm{~T}$ MRI instead of 3.0T MRI, which is likely more sensitive in detecting small WMH lesions. Clinical 3.0T MRI scanners were not readily available during the inclusion period of our study, starting in 2001. Second, we did not categorize deep $\mathrm{WMH}$ into lesions located directly under the cerebral cortex (i.e., infracortical) and those located more centrally in the subcortical white matter, which may differ in terms of etiology. ${ }^{38}$ Third, MRI sequences were used with a relatively large slice thickness of $4 \mathrm{~mm}$, which is likely less accurate in determining WMH shape markers than 3D MRI sequences. The impact of slice thickness, however, may be less profound on measurements of the concavity index as it is calculated by determining volume and surface area ratios of periventricular or confluent $\mathrm{WMH}$, which are expected to remain relatively constant. ${ }^{14}$ On the other hand, a more profound impact can be expected on measurements of the fractal dimension, which is directly dependent on voxel size. ${ }^{14} \mathrm{~A}$ larger slice thickness will therefore lead to reduced information in the $z$-axis. Similarly, shape determination of smaller deep WMH in the size range of several millimeters may also be affected by a relatively large slice thickness. Despite this limitation, however, we were able to detect associations between WMH shape markers and clinical outcomes, suggesting that WMH shape may represent a clinically relevant marker for occurrence of ischemic stroke and death.

Our findings demonstrate that WMH volume, type, and shape are associated with long-term risk of mortality and ischemic stroke in patients with manifest arterial disease. These findings suggest that WMH markers on MRI may be useful in determining patient prognosis and may aid in future patient selection for preventive treatment.

\section{Acknowledgment}

The authors thank the research nurses, $\mathrm{R}$. van Petersen (data manager), and B. van Dinther (study manager).

\section{Study Funding}

Funding for this article was received as part of a grant from the Netherlands Organization for Scientific Research-Medical Sciences (NWO-MW: project 904-65-095). This funding source had no role in the design, data collection, data analyses, or data interpretation of the study or writing of the report. Funding also was received from the European Research Council under the European Union's Horizon 2020 Programme (H2020)/ERC grant agreements 637024 and 66681 (SVDs@target).

\section{Disclosure}

The authors report no disclosures. Go to Neurology.org/ $\mathrm{N}$ for full disclosures.

\section{Publication History}

Received by Neurology July 5, 2020. Accepted in final form January 28, 2021. 
Appendix 1 Authors

\begin{tabular}{|c|c|c|}
\hline Name & Location & Contribution \\
\hline $\begin{array}{l}\text { Rashid } \\
\text { Ghaznawi, } \\
\text { MD, MSc }\end{array}$ & $\begin{array}{l}\text { Julius Center for Health } \\
\text { Sciences and Primary Care, } \\
\text { Department of Radiology, } \\
\text { University Medical Center } \\
\text { Utrecht and Utrecht } \\
\text { University, the Netherlands }\end{array}$ & $\begin{array}{l}\text { Literature search, figures, } \\
\text { data collection, MRI } \\
\text { processing, data analysis, } \\
\text { data interpretation and } \\
\text { writing }\end{array}$ \\
\hline $\begin{array}{l}\text { Mirjam I. } \\
\text { Geerlings, } \\
\text { PhD }\end{array}$ & $\begin{array}{l}\text { Julius Center for Health } \\
\text { Sciences and Primary Care, } \\
\text { University Medical Center } \\
\text { Utrecht and Utrecht } \\
\text { University, the Netherlands }\end{array}$ & $\begin{array}{l}\text { Study design, data analysis } \\
\text { and interpretation, critically } \\
\text { reviewed the manuscript }\end{array}$ \\
\hline $\begin{array}{l}\text { Myriam } \\
\text { Jaarsma- } \\
\text { Coes, MSc }\end{array}$ & $\begin{array}{l}\text { Department of Radiology, } \\
\text { Leiden University Medical } \\
\text { Center, the Netherlands }\end{array}$ & $\begin{array}{l}\text { MRI processing, data } \\
\text { analysis, data } \\
\text { interpretation, critically } \\
\text { reviewed the manuscript }\end{array}$ \\
\hline $\begin{array}{l}\text { Jeroen } \\
\text { Hendrikse, } \\
\text { MD, PhD }\end{array}$ & $\begin{array}{l}\text { Department of Radiology, } \\
\text { University Medical Center } \\
\text { Utrecht and Utrecht } \\
\text { University, the Netherlands }\end{array}$ & $\begin{array}{l}\text { Critically reviewed the } \\
\text { manuscript }\end{array}$ \\
\hline $\begin{array}{l}\text { Jeroen de } \\
\text { Bresser, } \\
\text { MD, PhD }\end{array}$ & $\begin{array}{l}\text { Department of Radiology, } \\
\text { Leiden University Medical } \\
\text { Center, the Netherlands }\end{array}$ & $\begin{array}{l}\text { Study design, data } \\
\text { interpretation, critically } \\
\text { reviewed the manuscript }\end{array}$ \\
\hline
\end{tabular}

Appendix 2 The Utrecht Cardiovascular Cohort-Second Manifestations of Arterial Disease Study Group

\begin{tabular}{lll}
\hline Name & Location & Role \\
\hline F.L.J. & University Medical & Chairman; \\
Visseren, & Center Utrecht, & co- \\
MD, PhD & Utrecht University, & investigator; \\
& the Netherlands & $\begin{array}{l}\text { SMART study } \\
\text { contributor }\end{array}$
\end{tabular}

Contribution

Critical review,

responsible for

data integrity,

responsible for

endpoint

adjudication

\begin{tabular}{lll}
\hline F.W. & University Medical & Co- \\
Asselbergs, & Center Utrecht, & investigator; \\
MD, PhD & Utrecht University, & SMART study \\
& the Netherlands & contributor
\end{tabular}

Critical review,

responsible for

data integrity,

responsible for

endpoint

adjudication

\begin{tabular}{lll}
\hline H.M. & University Medical & Co- \\
Nathoe, & Center Utrecht, & investigator; \\
MD, PhD & Utrecht University, & SMART study \\
& the Netherlands & contributor
\end{tabular}

Critical review,

responsible for

data integrity,

responsible for

endpoint

adjudication

\begin{tabular}{ll}
\hline M.L. Bots, & Julius Center for \\
MD, PhD & Health Sciences and \\
& Primary Care, \\
& University Medical \\
& Center Utrecht and \\
& Utrecht University, \\
& the Netherlands
\end{tabular}

Co- Critical review

investigator; responsible for

SMART study data integrity

contributor responsible for

endpoint

adjudication

\begin{tabular}{lll}
\hline M.H. & University Medical & Co- \\
Emmelot, & Center Utrecht, & investigator; \\
MD, PhD & Utrecht University, & SMART study \\
& the Netherlands & contributor
\end{tabular}

\begin{tabular}{lll}
\hline G.J. de & University Medical & Co- \\
Borst, MD, & Center Utrecht, & investigator; \\
PhD & Utrecht University, & SMART study \\
& the Netherlands & contributor
\end{tabular}

Critical review, responsible for data integrity, responsible for endpoint adjudication

Critical review responsible for data integrity, responsible for endpoint adjudication
Appendix 2 (continued)

\begin{tabular}{|c|c|c|c|}
\hline Name & Location & Role & Contribution \\
\hline $\begin{array}{l}\text { L.J. } \\
\text { Kappelle, } \\
\text { MD, PhD }\end{array}$ & $\begin{array}{l}\text { University Medical } \\
\text { Center Utrecht, } \\
\text { Utrecht University, } \\
\text { the Netherlands }\end{array}$ & $\begin{array}{l}\text { Co- } \\
\text { investigator; } \\
\text { SMART study } \\
\text { contributor }\end{array}$ & $\begin{array}{l}\text { Critical review, } \\
\text { responsible for } \\
\text { data integrity, } \\
\text { responsible for } \\
\text { endpoint } \\
\text { adjudication }\end{array}$ \\
\hline $\begin{array}{l}\text { T. Leiner, } \\
\text { MD, PhD }\end{array}$ & $\begin{array}{l}\text { University Medical } \\
\text { Center Utrecht, } \\
\text { Utrecht University, } \\
\text { the Netherlands }\end{array}$ & $\begin{array}{l}\text { Co- } \\
\text { investigator; } \\
\text { SMART study } \\
\text { contributor }\end{array}$ & $\begin{array}{l}\text { Responsible for } \\
\text { data integrity, } \\
\text { responsible for } \\
\text { endpoint } \\
\text { adjudication }\end{array}$ \\
\hline $\begin{array}{l}\text { P.A. de } \\
\text { Jong, MD, } \\
\text { PhD }\end{array}$ & $\begin{array}{l}\text { University Medical } \\
\text { Center Utrecht, } \\
\text { Utrecht University, } \\
\text { the Netherlands }\end{array}$ & $\begin{array}{l}\text { Co- } \\
\text { investigator; } \\
\text { SMART study } \\
\text { contributor }\end{array}$ & $\begin{array}{l}\text { Critical review, } \\
\text { responsible for } \\
\text { data integrity, } \\
\text { responsible for } \\
\text { endpoint } \\
\text { adjudication }\end{array}$ \\
\hline $\begin{array}{l}\text { A.T. Lely, } \\
\text { MD, PhD }\end{array}$ & $\begin{array}{l}\text { University Medical } \\
\text { Center Utrecht, } \\
\text { Utrecht University, } \\
\text { the Netherlands }\end{array}$ & $\begin{array}{l}\text { Co- } \\
\text { investigator; } \\
\text { SMART study } \\
\text { contributor }\end{array}$ & $\begin{array}{l}\text { Critical review, } \\
\text { responsible for } \\
\text { data integrity, } \\
\text { responsible for } \\
\text { endpoint } \\
\text { adjudication }\end{array}$ \\
\hline $\begin{array}{l}\text { N.P. van der } \\
\text { Kaaij, MD, } \\
\text { PhD }\end{array}$ & $\begin{array}{l}\text { University Medical } \\
\text { Center Utrecht, } \\
\text { Utrecht University, } \\
\text { the Netherlands }\end{array}$ & $\begin{array}{l}\text { Co- } \\
\text { investigator; } \\
\text { SMART study } \\
\text { contributor }\end{array}$ & $\begin{array}{l}\text { Critical review, } \\
\text { responsible for } \\
\text { data integrity, } \\
\text { responsible for } \\
\text { endpoint } \\
\text { adjudication }\end{array}$ \\
\hline $\begin{array}{l}\text { Y. Ruigrok, } \\
\text { MD, PhD }\end{array}$ & $\begin{array}{l}\text { University Medical } \\
\text { Center Utrecht, } \\
\text { Utrecht University, } \\
\text { the Netherlands }\end{array}$ & $\begin{array}{l}\text { Co- } \\
\text { investigator; } \\
\text { SMART study } \\
\text { contributor }\end{array}$ & $\begin{array}{l}\text { Critical review, } \\
\text { responsible for } \\
\text { data integrity, } \\
\text { responsible for } \\
\text { endpoint } \\
\text { adjudication }\end{array}$ \\
\hline $\begin{array}{l}\text { M.C. } \\
\text { Verhaar, } \\
\text { MD, PhD }\end{array}$ & $\begin{array}{l}\text { University Medical } \\
\text { Center Utrecht, } \\
\text { Utrecht University, } \\
\text { the Netherlands }\end{array}$ & $\begin{array}{l}\text { Co- } \\
\text { investigator; } \\
\text { SMART study } \\
\text { contributor }\end{array}$ & $\begin{array}{l}\text { Critical review, } \\
\text { responsible for } \\
\text { data integrity, } \\
\text { responsible for } \\
\text { endpoint } \\
\text { adjudication }\end{array}$ \\
\hline $\begin{array}{l}\text { J. } \\
\text { Westerink, } \\
\text { MD, PhD }\end{array}$ & $\begin{array}{l}\text { University Medical } \\
\text { Center Utrecht, } \\
\text { Utrecht University, } \\
\text { the Netherlands }\end{array}$ & $\begin{array}{l}\text { Co- } \\
\text { investigator; } \\
\text { SMART study } \\
\text { contributor }\end{array}$ & $\begin{array}{l}\text { Critical review, } \\
\text { responsible for } \\
\text { data integrity, } \\
\text { responsible for } \\
\text { endpoint } \\
\text { adjudication }\end{array}$ \\
\hline
\end{tabular}

\section{References}

1. Debette S, Markus HS. The clinical importance of white matter hyperintensities on brain magnetic resonance imaging: systematic review and meta-analysis. BMJ 2010;341:c3666.

2. Wardlaw JM, Smith C, Dichgans M. Mechanisms of sporadic cerebral small vessel disease: insights from neuroimaging. Lancet Neurol 2013;12:483-497.

3. Prins ND, Scheltens P. White matter hyperintensities, cognitive impairment and dementia: an update. Nat Rev Neurol 2015;11:157-165.

4. Wardlaw JM, Smith EE, Biessels GJ, et al. Neuroimaging standards for research into small vessel disease and its contribution to ageing and neurodegeneration. Lancet Neurol 2013;12:822-838.

5. Ostergaard L, Engedal TS, Moreton F, et al. Cerebral small vessel disease: capillary pathways to stroke and cognitive decline. J Cereb Blood Flow Metab 2016;36:302-325.

6. Gouw AA, Seewann A, van der Flier WM, et al. Heterogeneity of small vessel disease: a systematic review of MRI and histopathology correlations. J Neurol Neurosurg Psychiatry 2011;82:126-135.

7. Fazekas F, Kleinert R, Offenbacher $\mathrm{H}$, et al. The morphologic correlate of incidental punctate white matter hyperintensities on MR images. AJNR Am J Neuroradiol 1991; 12:915-921.

8. Fazekas F, Kleinert R, Offenbacher H, et al. Pathologic correlates of incidental MRI white matter signal hyperintensities. Neurology 1993;43:1683-1689.

9. Schmidt R, Fazekas F, Kleinert G, et al. Magnetic resonance imaging signal hyperintensities in the deep and subcortical white matter. A comparative study between stroke patients and normal volunteers. Arch Neurol 1992;49:825-827. 
10. Gouw AA, van der Flier WM, Fazekas F, et al. Progression of white matter hyperintensities and incidence of new lacunes over a 3-year period: the Leukoaraiosis and Disability Study. Stroke 2008;39:1414-1420.

11. van Dijk EJ, Prins ND, Vrooman HA, et al. Progression of cerebral small vessel disease in relation to risk factors and cognitive consequences: Rotterdam Scan Study. Stroke 2008;39:2712-2719.

12. Kloppenborg RP, Nederkoorn PJ, Grool AM, et al. Cerebral small-vessel disease and progression of brain atrophy: the SMART-MR study. Neurology 2012;79: 2029-2036.

13. Kim KW, MacFall JR, Payne ME. Classification of white matter lesions on magnetic resonance imaging in elderly persons. Biol Psychiatry 2008;64:273-280.

14. Ghaznawi R, Geerlings MI, Jaarsma-Coes MG, et al. The association between lacunes and white matter hyperintensity features on MRI: the SMART-MR study. J Cereb Blood Flow Metab 2019;39:2486-2496.

15. de Bresser J, Kuijf HJ, Zaanen K, et al. White matter hyperintensity shape and location feature analysis on brain MRI; proof of principle study in patients with diabetes. Sci Rep 2018;8:1893.

16. Kant IMJ, Mutsaerts H, van Montfort SJT, et al. The association between frailty and MRI features of cerebral small vessel disease. Sci Rep 2019;9:11343.

17. Geerlings MI, Appelman AP, Vincken KL, et al. Brain volumes and cerebrovascular lesions on MRI in patients with atherosclerotic disease: the SMART-MR study. Atherosclerosis 2010;210:130-136.

18. Goessens BM, Visseren FL, Kappelle LJ, et al. Asymptomatic carotid artery stenosis and the risk of new vascular events in patients with manifest arterial disease: the SMART study. Stroke 2007;38:1470-1475.

19. Ghaznawi R, Zwartbol MH, Zuithoff NP, et al. Reduced parenchymal cerebral blood flow is associated with greater progression of brain atrophy: the SMART-MR study. J Cereb Blood Flow Metab 2020:271678x20948614.

20. Anbeek P, Vincken KL, van Bochove GS, et al. Probabilistic segmentation of brain tissue in MR imaging. Neuroimage 2005;27:795-804.

21. Kempton MJ, Underwood TS, Brunton S, et al. A comprehensive testing protocol for MRI neuroanatomical segmentation techniques: evaluation of a novel lateral ventricle segmentation method. Neuroimage 2011;58:1051-1059.

22. Fazekas F, Chawluk JB, Alavi A, et al. MR signal abnormalities at $1.5 \mathrm{~T}$ in Alzheimer's dementia and normal aging. AJR Am J Roentgenol 1987;149:351-356.

23. Fazekas F, Barkhof F, Wahlund LO, et al. CT and MRI rating of white matter lesions. Cerebrovasc Dis 2002;13(suppl 2):31-36.

24. Liu EJ, Cashman KV, Rust AC. Optimising shape analysis to quantify volcanic ash morphology. GeoResJ 2015;8:14-30.
25. Zhang L, Liu JZ, Dean D, et al. A three-dimensional fractal analysis method for quantifying white matter structure in human brain. J Neurosci Methods 2006;150: 242-253.

26. Esteban FJ, Sepulcre J, de Miras JR, et al. Fractal dimension analysis of grey matter in multiple sclerosis. J Neurol Sci 2009;282:67-71.

27. Loizou CP, Petroudi S, Seimenis I, et al. Quantitative texture analysis of brain white matter lesions derived from T2-weighted MR images in MS patients with clinically isolated syndrome. J Neuroradiol 2015;42:99-114.

28. Murphy K, van Ginneken B, Schilham AM, et al. A large-scale evaluation of automatic pulmonary nodule detection in chest CT using local image features and k-nearestneighbour classification. Med Image Anal 2009;13:757-770.

29. White IR, Royston P, Wood AM. Multiple imputation using chained equations: issues and guidance for practice. Stat Med 2011;30:377-399.

30. Weinstein G, Wolf PA, Beiser AS, et al. Risk estimations, risk factors, and genetic variants associated with Alzheimer's disease in selected publications from the Framingham Heart Study. J Alzheimers Dis 2013;33(suppl 1):S439-S445.

31. Lim JS, Hong KS, Kim GM, et al. Cerebral microbleeds and early recurrent stroke after transient ischemic attack: results from the Korean Transient Ischemic Attack Expression Registry. JAMA Neurol 2015;72:301-308.

32. Kuller LH, Arnold AM, Longstreth WT Jr, et al. White matter grade and ventricular volume on brain MRI as markers of longevity in the Cardiovascular Health Study. Neurobiol Aging 2007;28:1307-1315.

33. Henneman WJ, Sluimer JD, Cordonnier C, et al. MRI biomarkers of vascular damage and atrophy predicting mortality in a memory clinic population. Stroke 2009;40:492-498.

34. Debette S, Beiser A, DeCarli C, et al. Association of MRI markers of vascular brain injury with incident stroke, mild cognitive impairment, dementia, and mortality: the Framingham Offspring Study. Stroke 2010;41:600-606.

35. Pantoni L. Cerebral small vessel disease: from pathogenesis and clinical characteristics to therapeutic challenges. Lancet Neurol 2010;9:689-701.

36. Rost NS, Rahman RM, Biffi A, et al. White matter hyperintensity volume is increased in small vessel stroke subtypes. Neurology 2010;75:1670-1677.

37. Conijn MM, Kloppenborg RP, Algra A, et al. Cerebral small vessel disease and risk of death, ischemic stroke, and cardiac complications in patients with atherosclerotic disease: the Second Manifestations of Arterial Disease-Magnetic Resonance (SMART-MR) study. Stroke 2011;42:3105-3109.

38. Wiggins ME, Jones J, Tanner JJ, et al. Pilot investigation: older adults with atrial fibrillation demonstrate greater brain leukoaraiosis in infracortical and deep regions relative to non-atrial fibrillation peers. Front Aging Neurosci 2020;12:271. 


\section{Neurology}

\section{Association of White Matter Hyperintensity Markers on MRI and Long-term Risk of Mortality and Ischemic Stroke: The SMART-MR Study}

Rashid Ghaznawi, Mirjam I. Geerlings, Myriam Jaarsma-Coes, et al. Neurology 2021;96;e2172-e2183 Published Online before print March 16, 2021

DOI 10.1212/WNL.0000000000011827

\section{This information is current as of March 16, 2021}

\section{Updated Information \& Services}

References

Citations

Subspecialty Collections

Permissions \& Licensing

Reprints including high resolution figures, can be found at: http://n.neurology.org/content/96/17/e2172.full

This article cites 37 articles, 12 of which you can access for free at: http://n.neurology.org/content/96/17/e2172.full\#ref-list-1

This article has been cited by 1 HighWire-hosted articles: http://n.neurology.org/content/96/17/e2172.full\#\#otherarticles

This article, along with others on similar topics, appears in the following collection(s):

\section{All Cerebrovascular disease/Stroke}

http://n.neurology.org/cgi/collection/all_cerebrovascular_disease_strok $\mathrm{e}$

\section{Cohort studies}

http://n.neurology.org/cgi/collection/cohort_studies

\section{Infarction}

http://n.neurology.org/cgi/collection/infarction

MRI

http://n.neurology.org/cgi/collection/mri

Stroke prevention

http://n.neurology.org/cgi/collection/stroke_prevention

Information about reproducing this article in parts (figures,tables) or in its entirety can be found online at:

http://www.neurology.org/about/about_the_journal\#permissions

Information about ordering reprints can be found online:

http://n.neurology.org/subscribers/advertise

Neurology ${ }^{\circledR}$ is the official journal of the American Academy of Neurology. Published continuously since 1951, it is now a weekly with 48 issues per year. Copyright Copyright ( 2021 The Author(s). Published by Wolters Kluwer Health, Inc. on behalf of the American Academy of Neurology.. All rights reserved. Print ISSN: 0028-3878. Online ISSN: 1526-632X.

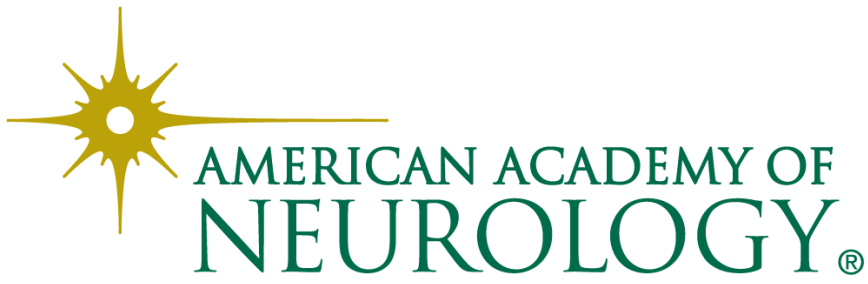

